\title{
Spherical Self-aggregates Formed with an Alanine-functionalized Porphyrin Derivative in Organic Solvent
}

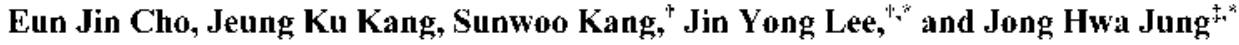 \\ Department of Materials Science and Engineering, KAIST, Daejeon 305-701, Korea \\ ${ }^{+}$Department of Chemistry, Sungkuzhkwan University, Suwon 440-746. Korea \\ Department of Chemistry and Research Institule for Natwal Science, Gyeongsang National University, Chinju 660-701, Korea \\ ${ }^{+}$E-mail: jonghwer(itgmiac: $k r$ \\ Received August 23, 2006
}

Key Words : Sell- $\Lambda$ ssembly, Porphyrin, Spherical, Nlanine

It is well known that porphyrins and phthalocyanines tend to align into one-dimensional aggregates and, therefore, are of much interest in relation to the creation of novel supramolecular architectures, such as nanowires, discotic liquid erystals, and helical riblon structures, etc. The major driving forces operating in these architectures are considered to be $\pi$ - $\pi$ stacking, intermolecular hydrogen bonding interactions, and/or van der Waals interactions. ${ }^{1-8}$ For example, Shinkai and co-workers reported that self-assembled porphyrin derivatives having amide groups efficiently form lïber structures by $\pi$ - $\pi$ stacking as well as through intermolecular hydrogen bonding interactions in organic solvents." Particularly, the hydrogen bond forming groups in porphyrin derivalives play an important role in the formation of the final aggregation mode. Therefore, we designed an alanine-functionalized porphyrin derivative in order 10 form seli-assembled superstruetures through internolecular hydrogen bonding interactions. The alanine-functionalized porphyrin is constructed by introducing four alkyl alanine residues onto the macrocyclic skelcton. We report here the preparation and the aggregate formation of 1 in organic solvent, as demonstrated by field-emission scanning electron microscopy (FГ-SГM), energy-filtered transmission electron microscopy (T:-TГM), confocal laser scanning microscopy (CISM), FT-IR, and fluorescence spectroscopy studies.

Alanine-lunctionalized porphyrin I was synthesized in six steps as shown in Scheme 1. The alanine ethyl ester was added to a solution of the cortesponding tetraphenyl carboxy acid 3. After de-cllyylation of 5 , treatment with 6 and diaminoacetylene 10 aflorded the desired product 1 as a dark brown powder. Also, compound 2 withoul alanine moicties was prepared as reference.

The aggregation behavior of 1 was investigated in organic solvents such as toluene or chlorolorm by using several microscopic, and spectroscopic methods. In order to obtain visual insights into the aggregation mode, we observed the superstructure of self-assembled 1 and 2 by FE-STEM and TE-TT:M. Figure 1 shows FT-SEM and TF-TFM images of the self-assembled 1 formed in toluene. The FE-SEM and ГЕ-ТГ:M images of unstained samples in toluene show a spherical struclure with uniform dianeter of $=600 \mathrm{~nm}$, which have no hollow cavity. In contrast, compound 2 which lacked alanine moiclies did not reveal any morphology due to high solubility in organic solvents. These results indicate that the alanine moicty plays a critical role in forming the self-assembled spherical structure. Also, the findings suggest that the self-assembled spherical structure of 1 might be induced mainly by strong internolecular hydrogen bonding interactions between alanine and alanine moieties in organic solvents.

Ilydrogen bonding interactions of alanine moieties of 1 in toluene were evaluated by FT-IR measurements and compared with those of $\mathbf{2}$ without the alanine moicty. The absorption frequencies originating from the N-II deformation band and from the $\mathrm{C}-\mathrm{O}$ stretching vibrations of 1 shifted to higher and lower wavenumbers (N-II: 1534 and C.-O: $1623 \mathrm{~cm}^{-1}$ ), as compared to the comparable absorption frequencies for the reference compound 2 (N-H: 1556 and c. $-0: 1638 \mathrm{~cm}^{-1}$ ), indicating the formation of hydrogen bonds for almost all the amide residues of 1 (Figure S1).

To have an insight on the role of hydrogen bonding between amide groups in the self-assembly of 1 , we simplified the molecule 1 by replacing the alkyl chain alter the amide group with methyl. It is clearly shown in Figure $\$ 2$ that the hydrogen bonding between amide groups play an important role in growing by self-assembly. In particular, all the four chains seem to be involved in the intermolecular hydrogen bonding in the self-assembly. The themnodynamic stability of uuuu, uudd, and udud structures is virtually equivalent (within $0.12 \mathrm{kcal} / \mathrm{mol}$ ) at the AM1 calculations (sec calculation results and Scheme S1 in Supporting Tnformation). In our experiment, the spherical self-assembled structure was
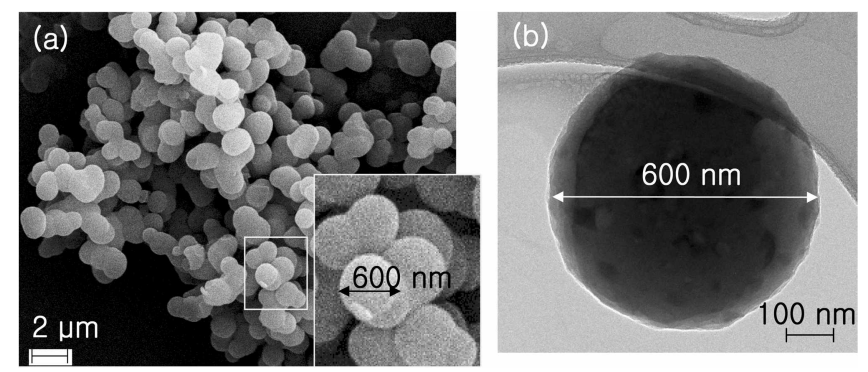

Figure 1. (a) Fl-SI:M and (b) I:F-TLM images of self-assembled 1 $(2.5 \mathrm{wt} \%)$ in toluene. 

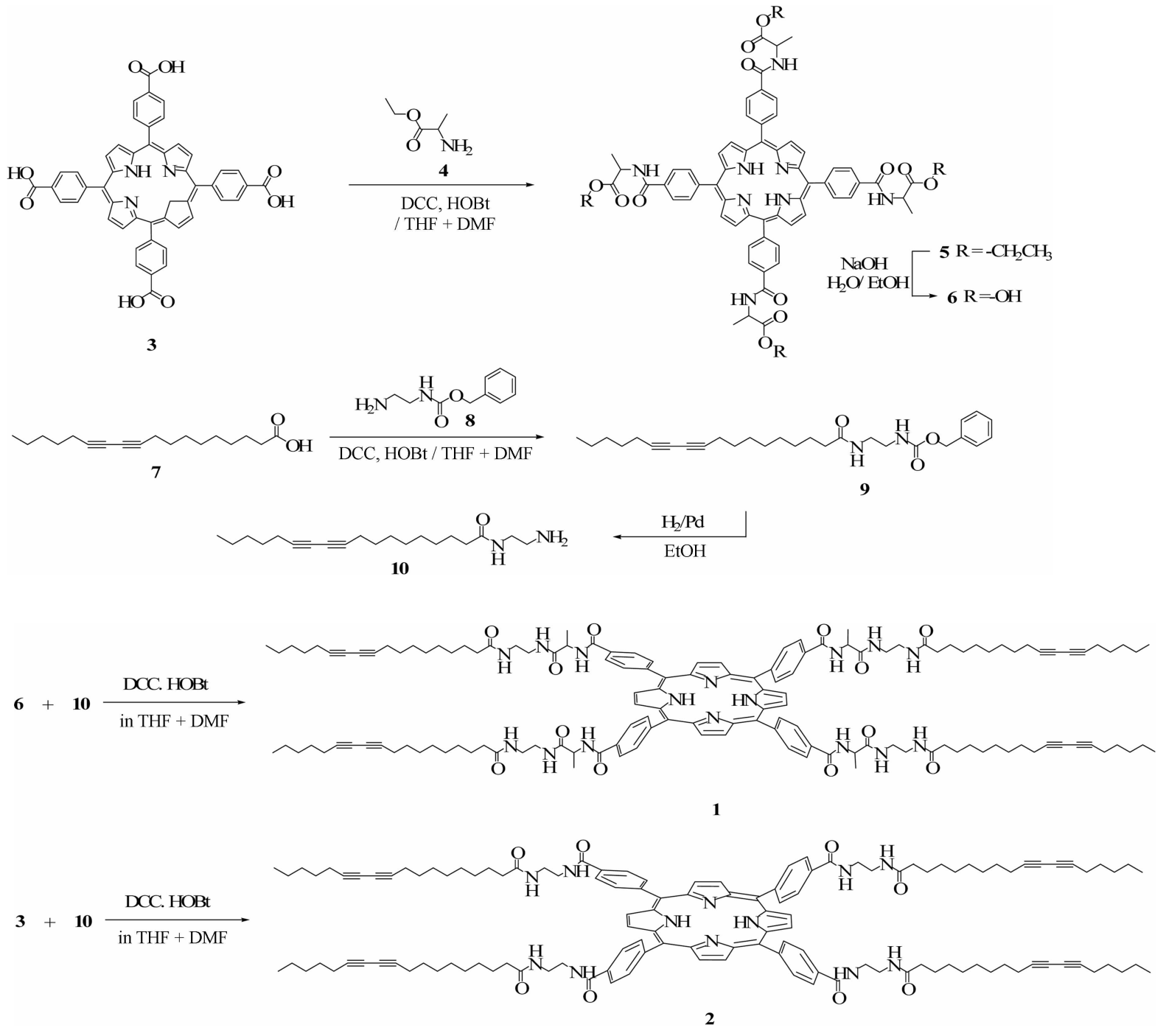

Scheme 1. Synthetic routes for alanine-functionalized porphyrin derivatives.

observed, thus, the building block is expected to be "udud" type structure because "udud" is the only structure that can result a 3 -dimensional network in self-assembly (Scheme S1).

To confirm the molecular packing structure, we measured the powder-X-ray diffraction pattern of the self-assembled 1 (Figure S3). The observed strong high-ordered reflection peak at $1.85^{\circ}$ indicates the existence of a well-organized layer structure. The $d$-spacing is calculated from the Bragg equation to be $47.7 \dot{A}$, which is estimated from CPK spacefilling model. This result suggests that the side chains around the alanine residues of 1 were well-assembled and constructed in a layer structure through inter- and intramolecular hydrogen bonds. Also, the long alkyl chain group of 1 forms the hydrophophic interaction.

Dye loading of the self-assembled 1 is conducted by licpuid-liquid phase transfer as shown in Figure S4. In liquidlicpuid phase transfer, an aqueous solution of the dye is transferred into a layer of the self-assembled 1.

To confirm encapsulation of rhodamine $\mathrm{B}$ molecules into the self-assembled 1, the rhodamine B adsorbed outside on the surface of the self-assembled spherical structure 1 was removed by washing with water. Then, we observed CLSM inages by excitation with $554 \mathrm{~nm}$. As shown in Figure 2, self-assembled 1 loaded with rhodamine B shows a spherical structure. This observation supports the notion that the majority of rhodamine $B$ present in the self-assembled nanosphericles is physically adsorbed. Also, the EF-TEM
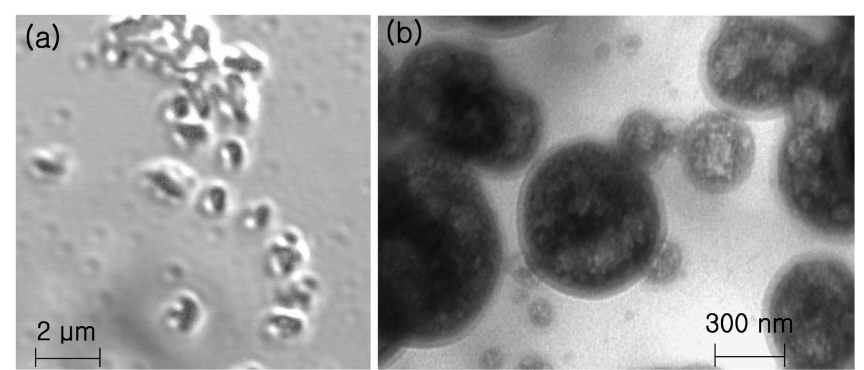

Figure 2. (a) CISM and (b) TLM inages of self-assembled 1 encapsulated with rhodamine B in toluene. 


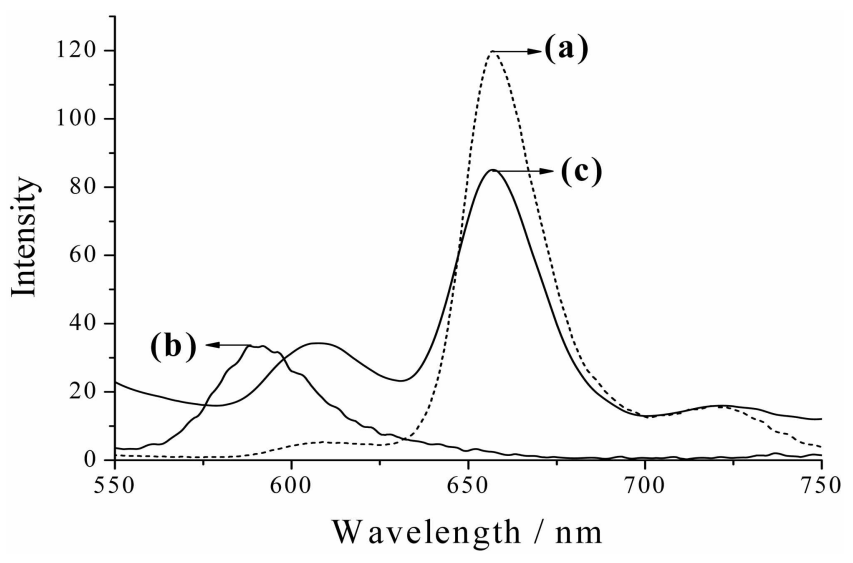

Figure 3. Fluorescent spectra of (a) self-assembled 1, (b) rhodamine 13 , and (c) 1 /rhodamine $B$ in toluene.

image of the self-assembled 1 encapsulated with rhodamine B reveatcu a spherical structure with - 600 illu diancice, indicating that after loading the rhodamine $B$ molecules, the spherical structure of the self-assembled 1 maintains stably by $\pi$ - $\pi$ stacking.

Furthermore, clear evidence for encapsulation of rhodamine $B$ in the self-assembled spheres 1 was oblained by fluerescence spectroscopy (Figure 3). The fluorescence emission spectum of the self-assembled 1 encapsulated with rhodamine $B$ in toluene shows peaks at 607 and 657 nom. Particularly, in the spectrum of nanoparticle encapsulated with rhodamine $B$, the emission intensity at $657 \mathrm{~nm}$ was less than that of 1 without rhodamine $B$, indicating that the rhodamine $B$ molecules are interealated between porphyrin and porphyrin moiclies by $\pi$ - $\pi$ stacking. In addition, the rhodamine $B$ fluoreseence in the self-assembled 1 was observed to shift to longer wavelength in comparison to rhodamine $B$ itself. The finding suggests that the rhodamine B was efficiently stacked between the porphyrin moieties.

In summary, porphyrin derivative 1 having four alanine moieties was found to form spherical self-aggregates in toluene as confirmed by EF-TEM and FE-SEM studies. The polar alanine groups of $\mathbf{1}$ play key roles for the formation of the aggregate. Also, the self-assembled aggregates have successfully encapsulated the guest molecule rhodamine B by $\pi-\pi$ stacking. We believe that this aggregate itself may have interesting applications as well. since multimolecular micelles are being studied for their use in fields such as drug delivery, diagnosis, separation technology, and optotechnology. To this purpose, we are currently investigating the structure of these aggregates in more detail, as well as the incorporation of functional additives into the aggregates.

\section{Experimental Section}

Compound $4^{(1)}$ and $8^{11}$ were prepared from the adaptation of the reported procedures.

Compound 1. Compound $6(0.2 \mathrm{~g}, 0.19 \mathrm{mmol})$ was dissolved in THF/DMF $(10: 1)$ and the solution cooled to 0 "C. Compound $10(0.3 \mathrm{~g}, 0.93 \mathrm{mmol}), 1,3$-Dicyclohexyl- carbodiunide (LCC, $0.19 \mathrm{~g}, 0.93 \mathrm{mmol}$ ), and 1-Hydroxybenzotriazole hydrate ( $\mathrm{HOBt}, 0.13 \mathrm{~g}, 0.93 \mathrm{mmol}$ ) were then added successively. The reaction mixture was refluxed for $15 \mathrm{~h}$. After removing the solvent, the residue was taken up in $\mathrm{CHCl}_{3}$ and washed with water. The organic solvent was evaporated to dryness. The residue was purified by a silicagel column eluting with $\mathrm{CHCl} / \mathrm{MeOH}$ to give compound 1 in yield $10 \%$ as dark brown solid. M.p. $230{ }^{\circ} \mathrm{C}$; ${ }^{1} \mathrm{H}-\mathrm{NMR}$ (C.DCl. $\left.+\mathrm{McOD}_{3} \mathrm{~d}_{1}\right): \delta=8.74(\mathrm{~m}, 8 \mathrm{H}, \mathrm{ArH}) 8.34(\mathrm{~m}, 16 \mathrm{H}$, $\mathrm{ArH}), 4.85$ (br s, $4 \mathrm{H},-\mathrm{NH}), 3.62\left(\mathrm{~m}, 16 \mathrm{H},-\mathrm{CH}_{2} \mathrm{CH}_{2}-\right), 2.32$ $-0.69\left(\mathrm{~m}, 72 \mathrm{H},-\mathrm{CH}_{2} \mathrm{CH}_{2}-\&-\mathrm{CH}_{3}\right)$.

Compound 2. TCPP [Tetrakis(4-carboxyphenyl)porphine] $3(0.50 \mathrm{~g}, 0.63 \mathrm{mmol})$ was dissolved in THF/DMF $(10: 1)$ and the solution cooled to 0 " $\mathrm{C}$. Compound $10(1,0 \mathrm{~g}$, $3.16 \mathrm{mmol})$, DCC $(0.65 \mathrm{~g}, 3.16 \mathrm{mmol})$, and HOK3t $(0.43 \mathrm{~g}$, $3.16 \mathrm{mmol})$ were then added suceessively.

A solution of tetrakis(4-carboxyphenyl)porphine $3(0.50$ g, $0.63 \mathrm{mmol})$, compound 10 (1.0 g, $3.16 \mathrm{mmol})$, J)CC $(0.65$ $\mathrm{g}, 3.16 \mathrm{mmol})$, and HOBt $(0.43 \mathrm{~g}, 3.16 \mathrm{mmol})$ were refluxed for $20 \mathrm{~h}$ in THF/DMF $(10: 1)$. The reaction mixture was refluxed for $20 \mathrm{~h}$. After removing the solvent, the residuc was taken up in $\mathrm{CHCl}_{3}$ and washed with water. The organic solvent was evaporated to dryness. The residue was purified by a silica-gel column eluting with $\mathrm{CHCl}_{3} / \mathrm{MeOH}$ to give compound 2 in yicld $20 \%$ as dark brown solid. M.p. $227{ }^{\circ} \mathrm{C}$; 'H-NMR (CJ)Cl $\left.\mathrm{I}_{3}\right): \delta=8.72-8.49(\mathrm{~m}, 16 \mathrm{H}, \mathrm{ArH}), 8.39$ (d, $J=$ $7.5 \mathrm{H} ., 8 \mathrm{H},-\mathrm{ArH}), 6.36$ (br s, $2 \mathrm{H}, \mathrm{NH}), 6.19$ (br s, $2 \mathrm{H}, \mathrm{NH}$ ), $4.91(\mathrm{bs}, 4 \mathrm{H}, \mathrm{NH}), 4.22\left(\mathrm{~m}, 4 \mathrm{H},-\mathrm{CH}_{2} \mathrm{CH}_{2}\right), 3.66(\mathrm{~m}, 12 \mathrm{H}$, $\left.-\mathrm{CH}_{2} \mathrm{CH}_{2}-\right), 2.36-0.79\left(\mathrm{~m}, 60 \mathrm{H},-\mathrm{CH}_{2} \mathrm{CH}_{2}-\&-\mathrm{CH}_{3}\right)$.

Compound 5. Tetrakis(4-carboxyphenyl)porphine $(0.5 \mathrm{~g}$, $0.63 \mathrm{mmol}$ ) was dissolved in THF/DMF (30:3) and the solution cooled to 0 "C. 1, 3-Dicyclohexylcarbodiimide (DCC, $0.59 \mathrm{~g}, 2.85 \mathrm{mmol}$ ), 1-Hydroxybenzotriazole hydrate (HOR3, $0.38 \mathrm{~g}, 2.85 \mathrm{mmol}$ ), Compound 4 (0.4 g, $2.85 \mathrm{mmol}$ ) and triethylamine $(0.2 \mathrm{mI}, 0.28 \mathrm{mmol})$ were then added sucessively. The reaction mixture was refluxed for $24 \mathrm{~h}$. The THF was then evaporated, and the residuce dissolved in water. The precipitated solid was filtered and purified by a silica-gel column eluting with $\mathrm{CHCl} / \mathrm{MeOH}$ to give compound 5 in yield $75 \%$ as dark brown solid. M.p. $270^{\circ} \mathrm{C}$; 'H-NMR (CDCl. $) ; \delta=8.84$ (s, $4 \mathrm{H}, \mathrm{ArH}$ ), 8.72 (d, $J=7.5$ Hz. 6H, ArH), 8.64 (br s, 2H, NH), 8.49 (m, $4 \mathrm{H}, \mathrm{ArH}$ ), 8.35$8.21(\mathrm{~m} .10 \mathrm{H}, \mathrm{ArH}), 4.99\left(\mathrm{q}, J=6.9 \mathrm{~Hz}, 4 \mathrm{H},-\mathrm{HNCH}\left(\mathrm{CH}_{3}\right)-\right)$. $4.35\left(\mathrm{q}, J=7.2 \mathrm{~Hz}, 8 \mathrm{H},-\mathrm{CH}_{2} \mathrm{CH}_{3}\right), 3.93(\mathrm{~d} . J=6.9 \mathrm{~Hz}, 4 \mathrm{H}$, $-\mathrm{NH}), 1.71\left(\mathrm{t}, J=7.2 \mathrm{~Hz}, 12 \mathrm{H},-\mathrm{CH}_{3}\right), 1.41(\mathrm{q}, J=7.2 \mathrm{~Hz}$, $\left.12 \mathrm{H},-\mathrm{CH}_{3}\right) ;{ }^{13} \mathrm{C}-\mathrm{NMR}\left(300 \mathrm{MHz}, \mathrm{CDCl}_{3}\right): \delta=173.70$ $(\mathrm{C}=\mathrm{O}), 167.18(\mathrm{C}=\mathrm{O}), 145.66(\mathrm{CH}), 134.85(\mathrm{CH}), 133.73$ (CH) $128.74(\mathrm{CH}), 125.80(\mathrm{CH}), 119.55(\mathrm{CH}), 62.08(\mathrm{CH})$, $52.98(\mathrm{CH}), 49.08(\mathrm{CH}), 49.00(\mathrm{CH}), 19.05(\mathrm{CH}), 18.98$ (CH), $14.45(\mathrm{CH})$.

Compound 6. Compound $5(1.0 \mathrm{~g}, 0.84 \mathrm{mmol})$ was dissolved in tetrahydrofuran $(20 \mathrm{~mL})$. The solution was cooled to $0^{\circ} \mathrm{C}$ and then aqueous sodium hydroxide solution $\left(0.3 \mathrm{~g}\right.$ in $\left.\mathrm{H}_{2} \mathrm{O}, 1.0 \mathrm{~mL}\right)$ was added. The reaction was stirred under nitrogen for 24 hours. The solvent was removed by rotary evaporation, water was added $(30 \mathrm{~mL})$ and then the mixture was acidified to $\mathrm{pH} 3$ with aqueous sodium hydro- 
gen sulfate. The product was extracted with ethylacetate and then washed with water and brine. The resulting solution was dried $\left(\mathrm{MgSO}_{4}\right)$ and then the solvent was removed by rotary evaporation to dryness. Diethyl ether $(20 \mathrm{~mL})$ was added and then solvent was removed from the mixture by rotary evaporation to give product $(0.55 \mathrm{~g}, 0.30 \mathrm{mmol}$, $76 \%$ ). M.p. $280-282{ }^{\circ} \mathrm{C} ;{ }^{1} \mathrm{H}-\mathrm{NMR}\left(300 \mathrm{MHz}, \mathrm{DMSO}-\mathrm{d}_{6}\right): \delta$ $=8.96(\mathrm{~d}, 4 \mathrm{H}, J=7.2 \mathrm{~Hz}, \mathrm{NH}), 8.87(\mathrm{~s}, 8 \mathrm{H}, \mathrm{ArH}), 8.36(\mathrm{~s}$, $16 \mathrm{H}, \mathrm{ArH}), 4.61\left(\mathrm{q}, 4 \mathrm{H},-\mathrm{NHC}\left(\mathrm{CH}_{3}\right) \mathrm{H}-\right), 1.53(\mathrm{~d}, 12 \mathrm{H}, J=$ $\left.7.2 \mathrm{~Hz},-\mathrm{CH}_{3}\right) ;{ }^{13} \mathrm{C}-\mathrm{NMR}\left(300 \mathrm{MHz}, \mathrm{DMSO}-\mathrm{d}_{6}\right): \delta=174.27$ $(\mathrm{C}=\mathrm{O}), 166.09(\mathrm{C}=\mathrm{O}), 144.01(\mathrm{CH}), 134.21(\mathrm{CH}), 134.11$ $(\mathrm{CH}), 126.10(\mathrm{CH}), 110.20(\mathrm{CH}), 92.97(\mathrm{CH}), 48.40(\mathrm{CH})$, $30.67(\mathrm{CH}), 17.02(\mathrm{CH}), 15.81(\mathrm{CH})$.

Compound 9. 10, 12-Octadecadiynoic acid (compound 7, $0.5 \mathrm{~g}, 1.81 \mathrm{mmol}$ ) was dissolved in THF/DMF (20:1) under a nitrogen atmosphere. The solution was maintained at $0{ }^{\circ} \mathrm{C}$ with an ice bath. The dicyclohexylcarbodiimide (DCC, $0.383 \mathrm{~g}, 1.86 \mathrm{mmol})$ and $\mathrm{HOBt}(0.022 \mathrm{~g}, 0.186 \mathrm{mmol})$, and compound $8(0.42 \mathrm{~g}, 2.17 \mathrm{mmol})$ were then added, the reaction mixture being stirred for $24 \mathrm{~h}$ at room temperature. After removing the solvent, the residue was taken up in $\mathrm{CHCl}_{3}$ and washed with water. The organic solvent was evaporated to dryness. The residue was purified by a silicagel column eluting with EA/n-Hexane to give compound 9 in yield $50 \%$ as white solid. M.p. $114{ }^{\circ} \mathrm{C} ;{ }^{1} \mathrm{H}-\mathrm{NMR}(300$ $\left.\mathrm{MHz}, \mathrm{CDCl}_{3}\right): \delta=7.80(\mathrm{~m}, 1 \mathrm{H}, \mathrm{ArH}), 7.46(\mathrm{~m}, 1 \mathrm{H}, \mathrm{ArH})$, $7.34(\mathrm{~m}, 3 \mathrm{H}, \mathrm{ArH}), 5.09\left(\mathrm{~s}, 2 \mathrm{H},-\mathrm{CH}_{2} \mathrm{C}_{6} \mathrm{H}_{5}\right), 3.35(\mathrm{~m}, 4 \mathrm{H}$, $\left.-\mathrm{NHCH}_{2} \mathrm{CH}_{2} \mathrm{NH}-\right), 2.23\left(\mathrm{~m}, 4 \mathrm{H},-\mathrm{CH}_{2}-\right), 2.14(\mathrm{t}, 2 \mathrm{H}, J=7.5$ $\left.\mathrm{Hz},-\mathrm{CH}_{2}-\right), 1.54-1.25\left(\mathrm{~m}, 20 \mathrm{H},-\mathrm{CH}_{2}-\right), 0.89(\mathrm{t}, 3 \mathrm{H}, J=6.9$ $\mathrm{Hz},-\mathrm{CH}_{2} \mathrm{CH}_{3}$ ).

Compound 10. Compound 9 ( $2.0 \mathrm{~g}, 4.42 \mathrm{mmol})$ was dissolved in a mixture of ethanol $(20 \mathrm{~mL})$. Then, $10 \% \mathrm{Pd}-\mathrm{C}$ $(25 \mathrm{mg})$ was added to the solution. Hydrogen gas was introduced into the mixed solution for $24 \mathrm{~h}$ at room temperature. The reaction mixture was filtered to remove $\mathrm{Pd}-\mathrm{C}$ and the filtrate was evaporated in vacuo to dryness. Yield 70\%, white solid. M.p. $109^{\circ} \mathrm{C}$; 'H-NMR (300 MHz, $\mathrm{CDCl}_{3}$ ): $\delta=4.17$ (br s, $2 \mathrm{H},-\mathrm{NHCH}_{2} \mathrm{CH}_{2}-$ ), 3.48 (br s, $2 \mathrm{H}$, $\left.-\mathrm{CH}_{2} \mathrm{CH}_{2} \mathrm{NH}_{2}\right), 1.97-0.89\left(\mathrm{~m}, 31 \mathrm{H},-\mathrm{CH}_{2} \mathrm{CH}_{2}\right.$ - and $\left.-\mathrm{CH}_{3}\right)$.

Acknowledgements. This work was supported in part by the KOSEF (F01-2004-10061-0) and KRF (KRF-2005-005J09703).

Supporting Information Available: FT-IR spectra of the self-assembled 1 and 2 and calculation results, XRD diffraction pattern and dye loading method of the selfassembled $\mathbf{1}$. This material is available via the Internet at hitp://www:kcsnet.or.ko/bkcs.

\section{References}

I. (a) Van Nostrum, C. F.; Picken, S. J.; Schouten, A.-J.; Nolte, R. J. M. J. An. Chem. Soc. 1995, 117,9957 . (b) Schenning, A. P. H.; Benneker, F. B. G.; Geurts, H. P. M.; Liu, X. Y.; Nolte, R. J. M. J. Am. Chem. Soc. 1996, 118, 8549. (c) Van Nostrum, C. F.; Nolte, R. J. M. Chem. Commm. 1996, 2385.

2. (a) Fuhrhop, J.-H.; Demoulin, C.; Boettcher, C.; Koning, J.; Siggel, U. J. Am. Chem. Soc. 1992, 114, 4159. (b) Bindig, U.; Schulz, A.; Fuhrhop, J.-H. New J. Chem. 1995, 19, 427 and references therein.

3. (a) Smolenyak, P.; Peterson, R.; Nebesny, K.; Torker, M.; O'Brien, D. F.; Armstrong, N. R. J. Am. Chem. Soc. 1999, 121, 8628. (b) Drager, A. S.; Zangmeister, R. A. P.; Armstrong, N. R; O'Brien, D. F. J. Am. Chem. Soc. 2001, 123,3595.

4. (a) Kimura, M.; Kitamura, T.; Muto, T.; Hanabusa, K.; Shirai, H.; Kobayashi, N. Chem. Letf. 2000, 1088. (b) Kimura, M.; Muto, T.; Takimoto, H.; Wada, K.; Ohta, K.; Hanabusa, K.; Shirai, H.; Kobayashi, N. Langmuir 2000, 16, 2078. (c) Kimura, M.; Wada, K.; Ohta, K.; Hanabusa, K.; Shirai, H.; Kobayashi, N. J. Am. Chem. Soc. 2001, 123, 2438.

5. (a) Imada. T.; Murakami, H.; Shinkai, S. J. Chen. Soc., Chen. Conmun 1994, 1557. (b) Arimori, S.; Takeuchi, M.; Shinkai, S. J. Am. Chem. Soc. 1996, 118,245 . (c) Arimori, S.; Takeuchi, M.; Shinkai, S. Sturamol, Sci, 1998, 5,1 .

6. Nagala, N.; Kugimiya, S.; Kobuke, Y. Chem. Commun, 2001, 689

7. Kawano, S.-I.; Tamaru, S.-I.; Fujita, N.; Shirkai, S. Chem, Eur. J. 2004, 10,343. and references therein.

8. Jung, J. H.; Rim, J. A.; Lee, S. J.; Lee, H.; Park, S. M.; Kim, B. H. Bull. Korean Chem. Soc. 2005, 26, 34.

9. (a) Kichida, K.; Fujila, N.; Sada, K.; Shirkai, S. J. Am. Chem. Soc. 2005, 127,7298 . (b) Shirakawa, M.; Fujita, N.; Shinkai, S. J. Am. Chem. Soc. 2005, 127, 4164. (c) Shirakawa, M.; Fujila, N.; Shinkai, S. J. Am. Chemi. Soc. 2003, $125,9902$.

10. Jakusch, T; Dörnyei, A.; Correia, I.; Rodrigues, L. M.; Tóth, G. K.; Kiss, T.; Costa Pessoa, J.; Marcão, S. Eur. J. Inorg. Chen. 2003, 2113.

11. Aoi, K.; Itoh, K.; Okada, M. Macromolectles 1997, 30, 8072. 